\title{
Effects of chronic d-amphetamine administration on the reinforcing strength of cocaine in rhesus monkeys
}

\author{
Paul W. Czoty, \\ Department of Physiology and Pharmacology, Center for the Neurobiology of Addiction \\ Treatments (CNAT), Wake Forest University School of Medicine, Medical Center Boulevard, \\ Winston-Salem, NC 27157-1083, USA \\ Jennifer L. Martelle, and \\ Department of Physiology and Pharmacology, Center for the Neurobiology of Addiction \\ Treatments (CNAT), Wake Forest University School of Medicine, Medical Center Boulevard, \\ Winston-Salem, NC 27157-1083, USA

\section{Michael A. Nader \\ Department of Physiology and Pharmacology, Center for the Neurobiology of Addiction \\ Treatments (CNAT), Wake Forest University School of Medicine, Medical Center Boulevard, Winston-Salem, NC 27157-1083, USA} \\ Department of Radiology, Center for the Neurobiology of Addiction Treatments (CNAT), Wake \\ Forest University School of Medicine, Winston-Salem, NC 27157-1083, USA
}

Michael A. Nader: mnader@wfubmc.edu

\begin{abstract}
Rationale-Agonist medications have been proven effective in treating opioid and nicotine dependence; results from clinical studies suggest that the indirect dopamine agonist $d$ amphetamine may reduce cocaine abuse. In preclinical studies, chronic $d$-amphetamine treatment decreased ongoing cocaine self-administration.
\end{abstract}

Objectives-The present study extended previous results by determining effects of chronic $d$ amphetamine treatment on the reinforcing strength of cocaine under conditions in which access to cocaine was suspended during $d$-amphetamine treatment.

Methods-Daily operant conditioning sessions consisted of morning access to food pellets delivered under a 50-response fixed-ratio schedule and evening access to cocaine $(0.005-0.48 \mathrm{mg} /$ $\mathrm{kg}$ per injection, i.v.) under a progressive-ratio schedule. After responding maintained by 0.045 $\mathrm{mg} / \mathrm{kg}$ per injection cocaine stabilized, self-administration sessions were suspended and $d$ amphetamine (0.01-0.1 mg/kg per hr, i.v.) was administered continuously for 5 days. On the following day, $d$-amphetamine treatment was discontinued and daily self-administration sessions resumed.

Results-Following termination of $d$-amphetamine treatment, food- and cocaine-maintained responding was decreased in a dose-related manner. Decreases in the reinforcing strength of cocaine were larger and lasted longer than effects on food reinforcement. However, cocaine selfadministration was unaltered if 6 days elapsed between discontinuation of $d$-amphetamine treatment and the next cocaine self-administration session. 
Conclusions-The necessity of a self-administration session in the presence of $d$-amphetamine suggests that the protracted decrease in cocaine self-administration may be a manifestation of behavioral tolerance. Regarding treatment of cocaine dependence, data suggest that prolonged $d$ amphetamine treatment may be necessary to produce a sustained reduction in the reinforcing effects of cocaine.

\section{Keywords}

Drug abuse; Medication development; $d$-Amphetamine; Cocaine; Rhesus monkey

Cocaine abuse and dependence persist as major public health problems in the USA and worldwide. An extensive list of drugs has been evaluated clinically for efficacy in decreasing various measures of cocaine abuse (Vocci and Ling 2005). Although no medication has been approved by the Food and Drug Administration for clinical use, encouraging results have been observed with several compounds. One approach, agonist therapy, has been effective in the treatment of heroin and nicotine dependence (e.g., Kreek 2000; Silagy et al. 2004) and has received recent support for treating psychostimulant dependence (Grabowski et al. 2004a; Castells et al. 2007; Shearer 2008). In general, agonist medications share pharmacological mechanisms of action as well as physiological and behavioral effects with the abused drug. Because the abuse-related effects of cocaine have been most consistently linked to its effects on brain dopamine function (e.g., Woolverton and Johnson 1992), development of agonist medications for cocaine dependence has focused on drugs that enhance dopamine neurotransmission. The ideal agonist medication has a lower abuse potential than cocaine due to a slower onset and longer duration of action (for review, see Grabowski et al. 2004a). While efforts are ongoing to develop novel drugs with this profile (e.g., Carroll et al. 1999; Platt et al. 2002; Lile and Nader 2003; Rothman et al. 2005; Negus et al. 2007), drugs that are currently clinically available have been assessed in randomized trials (see Castells et al. 2007). For example, several studies have supported the safety and efficacy of $d$-amphetamine as a treatment for cocaine dependence (e.g., Fleming and Roberts 1994; White 2000; Shearer et al. 2003), including three double-blind, placebocontrolled studies that used a sustained-release preparation (Grabowski et al. 2001, 2004b; Shearer et al. 2003).

Preclinical studies of putative pharmacotherapies in laboratory animals are integral in designing clinical trials and predicting the likelihood of positive results. In particular, intravenous drug self-administration techniques have demonstrated predictive validity in characterizing the abuse liability of centrally acting drugs (Griffiths et al. 1980; Ator and Griffiths 2003) and have been used extensively to evaluate candidate pharmacotherapies for cocaine abuse (Mello and Negus 1996; Carroll et al. 1999; Howell and Wilcox 2001; Platt et al. 2002). Regarding agonist medications, laboratory studies in nonhuman primates have demonstrated that $d$-amphetamine can attenuate the reinforcing effects of cocaine under diverse conditions. Negus and Mello (2003b) reported that $d$-amphetamine treatment dosedependently decreased rates of ongoing cocaine-reinforced responding under a second-order schedule of reinforcement, shifting the cocaine dose-response curve rightward and downward. Moreover, $d$-amphetamine decreased cocaine choice when cocaine and food were concurrently available and decreased break points for cocaine under a progressive-ratio (PR) schedule (Negus 2003; Negus and Mello 2003a). Importantly, $d$-amphetamine was administered chronically in these studies. Examining the effects of chronic drug administration is critical for understanding the effectiveness of such drugs as medications not only because chronic administration better reflects ultimate clinical use but also because acute administration of $d$-amphetamine has been shown to alter the reinforcing effects of cocaine in a manner opposite to that of chronically administered $d$-amphetamine. For example, acutely administered $d$-amphetamine shifted the dose-effect curve for cocaine self- 
administration to the left and upward at a dose that had minimal effects on food-maintained responding (Barrett et al. 2004). Moreover, acute $d$-amphetamine has been shown to reinstate extinguished responding formerly maintained by cocaine (Gerber and Stretch 1975; de Wit and Stewart 1983). Under other conditions, acute $d$-amphetamine has been shown to decrease cocaine self-administration, but in these studies, similar reductions in foodmaintained responding were reported (Foltin and Evans 1999; Mansbach and Balster 1993).

The present study was designed to further characterize the effects of chronic $d$-amphetamine treatment on cocaine self-administration under a PR schedule of reinforcement in rhesus monkeys. Unlike previous studies in which cocaine was self-administered daily during $d$ amphetamine treatment, in the present experiments, access to cocaine was suspended during $d$-amphetamine treatment. It was hypothesized that the effects of $d$-amphetamine on subsequent behavior would be more purely assessed by eliminating access to cocaine during treatment, precluding the possibility of interactions between cocaine and $d$-amphetamine. Moreover, this regimen may more accurately reflect an experience in treatment in which an addict is able to refrain from using cocaine during a brief, initial period. To help distinguish whether reductions in cocaine self-administration resulted from an interaction between cocaine and $d$-amphetamine or a more persistent change in behavior that outlasted the pharmacological effects of $d$-amphetamine, an additional experiment was conducted in which 6 days elapsed between the termination of $d$-amphetamine treatment and the next cocaine self-administration session. Throughout these studies, the possibility that decreases in cocaine-reinforced responding were due to nonspecific alterations in responding was assessed by examining responding maintained by food that occurred daily on a separate manipulandum and by daily observation of the subjects.

\section{Materials and methods}

\section{Subjects and apparatus}

Four adult male rhesus monkeys (Macaca mulatta), each prepared with a chronic indwelling venous catheter and subcutaneous vascular access port (Access Technologies, Skokie, IL) under sterile surgical conditions as described previously (Czoty et al. 2006), served as subjects. Each monkey had an extensive history of cocaine self-administration and exposure to various monoamine transporter inhibitors (e.g., Lile et al. 2003). Monkeys were housed individually in sound-attenuating chambers $(0.91 \times 0.91 \times 0.91 \mathrm{~m}$; Plas Labs, Lansing, MI). The front wall of each cubicle was constructed of Plexiglas to allow the monkey visual access to the laboratory. Each cubicle was equipped with two response levers (BRS/LVE, Beltsville, MD). Four stimulus lights, alternating white and red, were located in a horizontal row above each lever. A food receptacle located between the levers was connected via tygon tubing to a pellet dispenser located outside the chamber for delivery of food pellets. Each animal was fitted with a stainless-steel harness and spring arm (Restorations Unlimited, Chicago, IL) that attached to the rear of the cubicle. A peristaltic infusion pump (ColeParmer Instrument Co., Vernon Hills, IL) was located on the top of the chamber for delivering injections at a rate of approximately $1.5 \mathrm{ml} / 10 \mathrm{~s}$. Monkeys also received fresh fruit, peanuts, and vegetables several days per week, and water was available ad libitum. Animal housing and handling and all experimental procedures were performed in accordance with the 2003 National Research Council Guidelines for the Care and Use of Mammals in Neuroscience and Behavioral Research and were approved by the Animal Care and Use Committee of Wake Forest University. Environmental enrichment was provided as outlined in the Animal Care and Use Committee of Wake Forest University Non-Human Primate Environmental Enrichment Plan. 


\section{Food-reinforced responding}

Monkeys were trained under a reinforcement schedule in which responding on the right lever resulted in delivery of one food pellet under a 50-response fixed-ratio (FR 50) schedule. Under the FR 50 schedule of reinforcement, white stimulus lights were illuminated and 50 responses resulted in the delivery of a food pellet, extinguishing of white lights, and illumination of red stimulus lights for $10 \mathrm{~s}$, followed by a 10-min timeout (TO) period during which no lights were illuminated and responding had no scheduled consequences. Sessions began at approximately 0830 hours each day and lasted for approximately $23 \mathrm{~h}$ or until the maximum number of allowed food reinforcers was earned. The number of pellets that could be earned was determined for each monkey as that required to provide enough food to maintain body weight, which was measured at least monthly, at approximately $95 \%$ of free-feeding levels. When monkeys earned fewer than the maximum number of food pellets, supplementary food (Purina Monkey Chow) was given at approximately 0800 hours in an amount calculated to raise the total grams of food to the desired level. Target food amounts for the monkeys in the present study were $130 \mathrm{~g}$ for three monkeys and $120 \mathrm{~g}$ for the fourth.

\section{Cocaine self-administration}

Monkeys self-administered (-) cocaine $\mathrm{HCl}$ (National Institute on Drug Abuse, Bethesda, MD, dissolved in sterile $0.9 \%$ saline) under a PR schedule of reinforcement in sessions that began at 1500 hours each day. At the beginning of the day (0800 hours), the pump was operated for approximately $30 \mathrm{~s}$ to fill the catheter with the drug solution available for that session; the PR schedule began at 1500 hours each day. Under the PR schedule, white stimulus lights were illuminated above the left lever, and 50 responses on that lever resulted in the first injection of the maintenance dose of cocaine $(0.045 \mathrm{mg} / \mathrm{kg}$ per injection $)$, extinguishing of white lights, and illumination of red stimulus lights for $10 \mathrm{~s}$, followed by a 10-min TO. The response requirement for subsequent injections was determined by the equation used by Richardson and Roberts (1996): ratio $=5 \times e^{(\text {reinforcer } \# \times 0.2)}-5$. For the present studies, the first response requirement ( 50 responses) corresponds to the 12 th value given by this equation and was followed by $62,77,95,117,144,177,218,267,328,402$, $492,602,737,901,1,102,1,347$, etc. Sessions ended when $2 \mathrm{~h}$ elapsed without an injection. Saline and other cocaine doses $(0.005-0.48 \mathrm{mg} / \mathrm{kg}$ per injection) were substituted for the maintenance dose of cocaine for at least 5 sessions and until responding stabilized $( \pm 20 \%$ of the mean number of injections for three consecutive sessions, with no trends) until a complete dose-effect curve was generated.

\section{Chronic d-amphetamine treatment}

Following determination of a cocaine dose-response curve, $0.045 \mathrm{mg} / \mathrm{kg}$ per injection cocaine was made available until responding stabilized. This dose of cocaine was chosen because it was situated on the ascending limb of the dose-response curve, permitting the detection of either increases or decreases in the reinforcing strength of cocaine. On the next day, administration of $d$-amphetamine began at approximately 0830 hours by connecting the external part of the catheter to an infusion pump outside the chamber (Cole-Parmer Instrument Co., Vernon Hills, IL). A single concentration of $d$-amphetamine was infused at a rate of $0.4 \mathrm{ml} / \mathrm{h}$ such that monkeys received $0.01,0.03$, or $0.1 \mathrm{mg} / \mathrm{kg} / \mathrm{h}$ for five consecutive days. The treatment duration was chosen because 5 days is typically required for responding to extinguish when saline is contingent on responding (see Table 1). Each monkey received all three $d$-amphetamine doses, with treatment doses tested in random order and separated by at least 14 days of baseline (i.e., no treatment) cocaine self-administration. In addition, food-reinforced responding was studied throughout treatment. On the morning of the sixth day, $d$-amphetamine treatment was discontinued and the catheter was flushed with heparin/ saline solution. At 1500 hours that afternoon, $0.045 \mathrm{mg} / \mathrm{kg}$ per injection cocaine was again 
made available for self-administration under the PR schedule of reinforcement, signaled by the illumination of the white stimulus lights above the right lever. Based on results from this experiment, a second experiment was conducted in three of these monkeys in which treatment for 5 days with $0.03 \mathrm{mg} / \mathrm{kg} / \mathrm{h} d$-amphetamine was followed by 6 days abstinence from treatment before the next cocaine self-administration session occurred. One of the authors (JLM) interacted with each monkey daily and noted informally any apparent unconditioned effects of $d$-amphetamine.

\section{Data analysis}

The dependent variable of primary interest was the number of cocaine injections earned under the PR schedule of reinforcement. In addition, the number food reinforcers received was recorded in hourly bins. For determining the cocaine dose-effect curve, data were averaged across the last 3 days of availability of each dose, then averaged across monkeys. Because average injections of $0.045 \mathrm{mg} / \mathrm{kg}$ cocaine differed across monkeys (raw values,

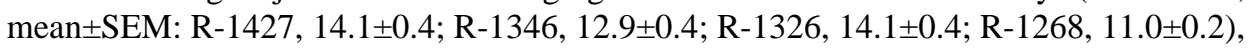
cocaine injections received after treatment with each $d$-amphetamine dose were expressed as a percentage of the mean number of reinforcers earned on the 3 days immediately preceding testing of that dose and presented as mean $( \pm \mathrm{SEM})$ for the group of monkeys. Similarly, food reinforcers earned during and after $d$-amphetamine treatment were expressed as a percentage of baseline. Food and cocaine reinforcers received (raw data) were analyzed with a repeated-measures one-way ANOVA, followed by post hoc Dunnett's tests to determine the days on which the number of reinforcers was significantly different from baseline. In all cases, differences were considered statistically significant at the $95 \%$ level of confidence $(p<0.05)$.

\section{Results}

\section{Baseline food- and cocaine-reinforced responding}

Under baseline conditions, monkeys earned all available food pellets within the first $3 \mathrm{~h}$ of availability in more than $95 \%$ of sessions (data not shown). Two subjects typically earned all available food reinforcers within the first hour of the session. In cocaine self-administration sessions, the number of injections received increased significantly as a function of the available cocaine dose $\left(F_{5,15}=37.28, p<0.0001\right.$, Fig. 1$)$. Post hoc analysis indicated injections received during availability of doses $\geq 0.015 \mathrm{mg} / \mathrm{kg}$ per injection cocaine differed significantly from the number of saline injections received under the PR schedule of reinforcement $(p<0.01)$. When saline was substituted for the baseline dose of $0.045 \mathrm{mg} / \mathrm{kg}$ cocaine, number of injections decreased in all monkeys (Table 1). When cocaine was again made available, number of injections increased on the first session of availability (Table 1).

\section{Effects of d-amphetamine on food-reinforced responding}

Chronic treatment with $d$-amphetamine resulted in a disruption of food-maintained responding (Fig. 2, top). This effect was progressive and related to $d$-amphetamine dose. No significant effects of $0.01 \mathrm{mg} / \mathrm{kg} / \mathrm{h} d$-amphetamine were observed during or after treatment, but higher $d$-amphetamine doses resulted in significant decreases in food-reinforced responding $\left(F_{15,45}=2.88, p<0.01\right.$ and $F_{15,45}=10.01, p<0.0001$ for 0.03 and $0.1 \mathrm{mg} / \mathrm{kg} / \mathrm{h}$, respectively) that became more prominent over the course of the 5-day treatment. It is important to note that during days that food-maintained responding was decreased, monkeys readily retrieved and ate food pellets when offered by experimenters and quickly ate all supplementary chows. In general, effects on total food reinforcers earned were reflected in the pattern of responding. Unlike under baseline conditions, in which all reinforcers were typically earned within $1-3 \mathrm{~h}$, responding during and immediately after treatment with 0.03 and $0.1 \mathrm{mg} / \mathrm{kg} / \mathrm{h} d$-amphetamine occurred at a low rate throughout the day. During this time, 
few overt unconditioned effects of $d$-amphetamine were noted. These were limited to mild agitation in three monkeys on 1 or 2 days during treatment with $0.1 \mathrm{mg} / \mathrm{kg} / \mathrm{h} d$-amphetamine characterized by a somewhat more aggressive reaction to the presence of lab personnel and less cooperative behavior during routine inspection of the vascular access port and catheter.

Following discontinuation of chronic $d$-amphetamine treatment, drug-induced decreases in food-reinforced responding dissipated over several days. The average number of reinforcers earned on the first 5 days after discontinuation of treatment with $0.03 \mathrm{mg} / \mathrm{kg} / \mathrm{h} d$ amphetamine remained below baseline levels, but differences were not statistically significant. After discontinuation of $0.1 \mathrm{mg} / \mathrm{kg} / \mathrm{h} d$-amphetamine, however, monkeys earned significantly fewer reinforcers for 4 days $(p<0.01)$ before responding recovered to baseline levels.

\section{Effects of d-amphetamine on subsequent cocaine self-administration}

Following termination of chronic $d$-amphetamine treatment, monkeys self-administered fewer $0.045 \mathrm{mg} / \mathrm{kg}$ cocaine injections under the PR schedule of reinforcement relative to baseline (Fig. 2, bottom). These reductions were related to the $d$-amphetamine dose administered. The effects of 0.03 and $0.1 \mathrm{mg} / \mathrm{kg} / \mathrm{h}$ were statistically significant $\left(F_{10,30}=7.17\right.$ and $F_{10,30}=15.51$, respectively; $p<0.0001$ for both doses), with post hoc analysis indicating significant reductions relative to baseline on days $1-4$ for both doses and on day 5 after 0.1 $\mathrm{mg} / \mathrm{kg} / \mathrm{h} d$-amphetamine.

\section{Effect of an intervening 6-day drug-free period}

In the second experiment, as in the first, 5 days of treatment with $0.03 \mathrm{mg} / \mathrm{kg} / \mathrm{h} d$ amphetamine significantly decreased food-reinforced responding $\left(F_{15,45}=5.43, p<0.0001\right.$; Fig. 3). Post hoc analysis indicated that the number of reinforcers earned on days 4 and 5 of treatment and on the following drug-free day differed significantly $(p<0.01)$ from baseline. Unlike the first experiment when cocaine reinforcement was studied 1 day after termination of $d$-amphetamine treatment, when access to cocaine was restored 5 days after treatment ended, the number of self-administered cocaine injections over the first 4 days was not different from baseline.

\section{Discussion}

Previous studies demonstrated that chronic administration of $d$-amphetamine decreases ongoing cocaine self-administration under a PR schedule of reinforcement and other conditions (Negus 2003; Negus and Mello 2003a, b; Chiodo et al. 2008; Chiodo and Roberts 2009). The results of the present study extend these findings to conditions under which cocaine self-administration is suspended during $d$-amphetamine treatment. Importantly, the intermediate dose of $d$-amphetamine reduced cocaine self-administration without significantly decreasing food-reinforced responding. The results suggest that administration of $d$-amphetamine during the initial portion of treatment, at a time in which a patient may be able to abstain from cocaine (either voluntarily or due to hospitalization), may result in reductions in the reinforcing strength of cocaine if use is resumed immediately after termination of treatment. The effectiveness of chronic $d$-amphetamine is reduced, however, if several days pass prior to cocaine use. These findings suggest that experiencing selfadministration while the agonist medication is present in the body is a critical aspect of effective treatment.

In initial experiments, $d$-amphetamine was administered continuously for 5 days. Chronic treatment with both 0.01 and $0.1 \mathrm{mg} / \mathrm{kg} / \mathrm{h} d$-amphetamine similarly affected food- and cocaine-maintained responding; neither behavior was altered significantly by $0.01 \mathrm{mg} / \mathrm{kg} / \mathrm{h}$ 
$d$-amphetamine whereas both were decreased significantly by $0.1 \mathrm{mg} / \mathrm{kg} / \mathrm{h} d$-amphetamine. Following chronic treatment with $0.03 \mathrm{mg} / \mathrm{kg} / \mathrm{h} d$-amphetamine, decreases in foodreinforced responding were modest and variable and, on average, not statistically significant. However, this $d$-amphetamine dose significantly decreased the reinforcing strength of 0.045 $\mathrm{mg} / \mathrm{kg}$ per injection cocaine for 4 days after the termination of $d$-amphetamine treatment. The potency of $d$-amphetamine to reduce cocaine self-administration in the present study was similar to that reported previously (Negus and Mello 2003a, b). Considering an elimination half-life of approximately $4.5 \mathrm{~h}$ for intravenous $d$-amphetamine (Beckett and Rowland 1965), it is clear that reductions in cocaine self-administration persisted beyond the time that $d$-amphetamine was present in the body. Thus, the sustained reduction in the reinforcing strength of cocaine over several days may represent a form of behavioral tolerance. That is, the experience of reduced reinforcing strength of cocaine in the presence of $d$-amphetamine on the first day after discontinuation of $d$-amphetamine treatment resulted in decreased self-administration over the next several days after treatment ended. This result in nonhuman primates is concordant with studies in humans in which the subjective effects of cocaine were reduced during chronic amphetamine treatment (Rush et al. 2009) but contrasts with findings from a recent study in rats in which 14 days of treatment with $d$ amphetamine did not alter post-treatment cocaine self-administration if access to cocaine was suspended during $d$-amphetamine treatment (Chiodo et al. 2008). The disconnect may be related to the amount of time that passed after chronic treatment. The first post-treatment self-administration session occurred immediately after termination of $d$-amphetamine treatment in the present study but did not occur until the following day in the Chiodo et al. (2008) study. Taken together, the data suggest that the presence versus absence of $d$ amphetamine in the body during the initial post-treatment self-administration session could be a critical variable accounting for the observed differences in effectiveness of chronic $d$ amphetamine. It is also worth noting that previous studies showed that simply allowing abstinence from cocaine for 3, 7, or 14 days did not alter the cocaine dose-effect curve (Czoty et al. 2006).

The possibility that behavioral tolerance was responsible for the reduction in selfadministration after $d$-amphetamine treatment was addressed in a second experiment in which 6 days elapsed after termination of treatment with $0.03 \mathrm{mg} / \mathrm{kg} / \mathrm{h} d$-amphetamine before availability of cocaine was restored. Although this dose of $d$-amphetamine significantly reduced the reinforcing strength of injections of $0.045 \mathrm{mg} / \mathrm{kg}$ cocaine for 4 days immediately after termination of treatment in the initial experiment, the number of selfadministered cocaine injections was not different from baseline values if 6 days intervened. These data support the hypothesis that experiencing cocaine self-administration in the presence of $d$-amphetamine after chronic treatment is necessary for the more prolonged decrease in cocaine self-administration to occur (e.g., Chiodo et al. 2008). One clinical implication of this finding is that continued treatment with an agonist medication may be necessary to produce a sustained reduction in the reinforcing effects of cocaine. In this respect, treatment with $d$-amphetamine is similar to treatment with other agonist medications such as methadone. An additional implication of these data is that daily amphetamine treatment may not be necessary in order to observe behavioral tolerance. Future studies will be needed to evaluate this hypothesis.

The prominent reduction of food-reinforced responding during and for several days after chronic treatment is likely due to disruptive effects of $d$-amphetamine on responding rather than to a reduction in appetite or the appetitive value of food pellets, as monkeys routinely took and ate chows, peanuts, food pellets, and other preferred foods when offered by a technician. Although this observation suggests that such disruptive effects also had a role in the observed reductions in cocaine self-administration, it is noteworthy that reductions in cocaine self-administration were larger and persisted longer than reductions in food- 
maintained responding. This finding parallels those of Negus and Mello (2003a, b), in which cocaine-reinforced responding was more sensitive to reduction by $d$-amphetamine than food-maintained responding. Moreover, Negus and Mello (2003b) observed tolerance to the effects of $0.1 \mathrm{mg} / \mathrm{kg} / \mathrm{h} d$-amphetamine on food- but not cocaine-reinforced responding after 8 days of chronic treatment. In addition, to the extent that disruptions in food-reinforced responding model side-effects experienced in patients, these data parallel clinical findings indicating a lack of serious adverse side-effects, and only mild side-effects in a limited number of patients, associated with chronic $d$-amphetamine treatment (Charnaud and Griffiths 1998; Shearer et al. 2001, 2003; Grabowski et al. 2001, 2004b). Other studies that have reported decreases in cocaine self-administration following acute administration of $d$ amphetamine have reported similar reductions in food-maintained responding (Foltin and Evans 1999; Mansbach and Balster 1993). Taken together, these data support the view that chronic treatment with agonist medications is more likely to produce selective reductions in cocaine self-administration than acute treatment (Negus and Mello 2003b). Two caveats to this interpretation in the present studies are that the experiment was not explicitly designed so that cocaine and food reinforcers would have equal reinforcing strength and that they were available under different schedules of reinforcement. These factors may have contributed to the apparent selectivity of the effects of $d$-amphetamine. However, Negus (2003) studied cocaine-food choice in which reinforcers were available under different FR schedules (FR 10 for cocaine and FR 100 for food) and found that $d$-amphetamine treatment significantly reduced cocaine choice.

One limitation of the present study is that only one dose of cocaine was examined, complicating interpretation of whether a decrease in the number of injections represents an effect akin to decreasing or increasing the cocaine dose. The monotonic nature of the curve suggests that a decrease in self-administration of $0.045 \mathrm{mg} / \mathrm{kg}$ per injection cocaine, a dose on the ascending limb, should be interpreted as a decrease the reinforcing strength of cocaine. It is possible that the dose-effect curve would have a biphasic, inverted $U$ shape if higher cocaine doses had been tested (e.g., Lile et al. 2003) and that $d$-amphetamine treatment could have decreased cocaine self-administration by interacting with $0.045 \mathrm{mg} / \mathrm{kg}$ cocaine injections in a manner that resulted in effects similar to those of a much higher dose of cocaine. Several factors argue against this hypothesis. First, the curve reached a plateau at the highest dose tested, $0.48 \mathrm{mg} / \mathrm{kg}$ per injection. In other studies from our laboratory, we have observed that that the descending limb does not appear until doses of at least $0.56 \mathrm{mg} /$ $\mathrm{kg}$ per injection. Thus, for a decrease in the number of injections to represent an effective increase in cocaine dose, treatment with $d$-amphetamine would have to cause the effects of $0.045 \mathrm{mg} / \mathrm{kg}$ cocaine injections to resemble those of a dose higher than $0.56 \mathrm{mg} / \mathrm{kg}$ per injection (i.e., over $1.0 \log$ units higher). Moreover, exposure to a dose of $d$-amphetamine this high would likely result in observable unconditioned behavioral effects such as locomotor activation and/or stereotopy, which were not seen in the present studies. Finally, it is noteworthy that a previous study that examined the complete cocaine dose-effect curve found that $d$-amphetamine shifted the entire dose-response curve rightward (Negus and Mello 2003b), clearly indicating antagonism, rather than enhancement, of the reinforcing effects of cocaine. The pattern of self-administration following discontinuation of amphetamine treatment in the present study was similar to the pattern of responding observed during saline extinction (Table 1), suggesting that the presence of amphetamine in the system decreased cocaine self-administration by attenuating the reinforcing strength of cocaine and further support the use of an agonist approach in treating cocaine dependence.

\section{Acknowledgments}

The authors thank Tonya Calhoun and Susan Nader for their assistance in completing these studies. This research was supported by NIDA grant P50 DA-06634. 


\section{References}

Ator NA, Griffiths RR. Principles of drug abuse liability assessment in laboratory animals. Drug Alcohol Depend. 2003; 5:S55-S72. [PubMed: 12759197]

Barrett AC, Miller JR, Dohrmann JM, Caine SB. Effects of dopamine indirect agonists and selective D1-like and D2-like agonists and antagonists on cocaine self-administration and food maintained responding in rats. Neuropsychopharmacology. 2004; 47 Suppl 1:256-273.

Beckett AH, Rowland M. Urinary excretion kinetics of amphetamine in man. J Pharm Pharmacol. 1965; 17:628-639. [PubMed: 4379686]

Carroll FI, Howell LL, Kuhar MJ. Pharmacotherapies for treatment of cocaine abuse: preclinical aspects. J Med Chem. 1999; 42:2721-2736. [PubMed: 10425082]

Castells X, Casas M, Vidal X, Bosch R, Roncero C, Ramos-Quiroga JA, Capella D. Efficacy of central nervous system stimulant treatment for cocaine dependence: a systematic review and meta-analysis of randomized controlled clinical trials. Addiction. 2007; 102:1871-1887. [PubMed: 18031423]

Charnaud B, Griffiths V. Levels of intravenous drug misuse among clients prescribed oral dexamphetamine or oral methadone: a comparison. Drug Alcohol Depend. 1998; 52:79-84. [PubMed: 9788010]

Chiodo KA, Roberts DC. Decreased reinforcing effects of cocaine following 2 weeks of continuous damphetamine treatment in rats. Psychopharmacology. 2009; 206:447-456. [PubMed: 19652955]

Chiodo KA, Lack CM, Roberts DC. Cocaine self-administration reinforced on a progressive ratio schedule decreases with continuous D-amphetamine treatment in rats. Psychopharmacology. 2008; 200:465-473. [PubMed: 18604521]

Czoty PW, Martelle JL, Nader MA. Influence of abstinence and conditions of cocaine access on the reinforcing strength of cocaine in nonhuman primates. Drug Alcohol Depend. 2006; 85:213-220. [PubMed: 16730922]

de Wit H, Stewart J. Drug reinstatement of heroin-reinforced responding in the rat. Psychopharmacology. 1983; 79:29-31. [PubMed: 6403961]

Fleming PM, Roberts D. Is the prescription of amphetamine justified as a harm reduction measure? J R Soc Health. 1994; 114:127-131. [PubMed: 7932481]

Foltin RW, Evans SM. The effects of d-amphetamine on intake of food and a sweet fluid containing cocaine. Pharmacol Biochem Behav. 1999; 62:457-464. [PubMed: 10080237]

Gerber GJ, Stretch R. Drug-induced reinstatement of extinguished self-administration behavior in monkeys. Pharmacol Biochem Behav. 1975; 3:1055-1061. [PubMed: 817297]

Grabowski J, Rhoades H, Schmitz J, Stotts A, Daruzska LA, Creson D, Moeller FG. Dextroamphetamine for cocaine-dependence treatment: a double-blind randomized clinical trial. J Clin Psychopharmacology. 2001; 21:522-526.

Grabowski J, Shearer J, Merrill J, Negus SS. Agonist-like, replacement pharmacotherapy for stimulant abuse and dependence. Addict Behav. 2004a; 29:1439-1464. [PubMed: 15345275]

Grabowski J, Rhoades H, Stotts A, Cowan K, Kopecky C, Dougherty A, Moeller FG, Hassan S, Schmitz J. Agonist-like or antagonist-like treatment for cocaine dependence with methadone for heroin dependence: two double-blind randomized clinical trials. Neuropsychopharmacology. 2004b; 29:969-981. [PubMed: 15039761]

Griffiths, RR.; Bigelow, GE.; Henningfield, JE. Similarities in animal and human drug-taking behavior. In: Mello, NK., editor. Advances in substance abuse. Vol. vol 1. Greenwich: JAI; 1980. p. $1-90$.

Howell LL, Wilcox KM. The dopamine transporter and cocaine medication development: drug selfadministration in nonhuman primates. J Pharmacol Exp Ther. 2001; 298:1-6. [PubMed: 11408518]

Kreek MJ. Methadone-related opioid agonist pharmacotherapy for heroin addiction. History, recent molecular and neurochemical research and future in mainstream medicine. Ann NY Acad Sci. 2000; 909:186-216. [PubMed: 10911931]

Lile JA, Nader MA. The abuse liability and therapeutic potential of drugs evaluated for cocaine addiction as predicted by animal models. Curr Neuropharmacol. 2003; 1:21-46. 
Lile JA, Wang Z, Woolverton WL, France JE, Gregg TC, Davies HM, Nader MA. The reinforcing efficacy of psychostimulants in rhesus monkeys: the role of pharmacokinetics and pharmacodynamics. J Pharmacol Exp Ther. 2003; 307:356-366. [PubMed: 12954808]

Mansbach RS, Balster RL. Effects of mazindol on behavior maintained or occasioned by cocaine. Drug Alcohol Depend. 1993; 31:183-191. [PubMed: 8436063]

Mello NK, Negus SS. Preclinical evaluation of pharmacotherapies for treatment of cocaine and opioid abuse using drug self-administration procedures. Neuropsychopharmacology. 1996; 14:375-424. [PubMed: 8726752]

Negus SS. Rapid assessment of choice between cocaine and food in rhesus monkeys: effects of environmental manipulations and treatment with d-amphetamine and flupenthixol. Neuropsychopharmacology. 2003; 28:909-931.

Negus SS, Mello NK. Effects of chronic d-amphetamine treatment on cocaine- and food-maintained responding under a progressive-ratio schedule in rhesus monkeys. Psychopharmacology. 2003a; 167:324-332. [PubMed: 12652348]

Negus SS, Mello NK. Effects of chronic d-amphetamine treatment on cocaine- and food-maintained responding under a second-order schedule in rhesus monkeys. Drug Alcohol Depend. 2003b; 70:39-52. [PubMed: 12681524]

Negus SS, Mello NK, Blough BE, Baumann MH, Rothman RB. Monoamine releasers with varying selectivity for dopamine/norepinephrine versus serotonin release as candidate "agonist" medications for cocaine dependence: studies in assays of cocaine discrimination and cocaine selfadministration in rhesus monkeys. J Pharmacol Exp Ther. 2007; 320:627-636. [PubMed: 17071819]

Platt DM, Rowlett JK, Spealman RD. Behavioral effects of cocaine and dopaminergic strategies for preclinical medication development. Psychopharmacology. 2002; 163:265-282. [PubMed: 12373428]

Richardson NR, Roberts DCS. Progressive ratio schedules in drug self-administration studies in rats: a method to evaluate reinforcing efficacy. J Neurosci Methods. 1996; 66:1-11. [PubMed: 8794935]

Rothman RB, Blough BE, Woolverton WL, Anderson KG, Negus SS, Mello NK, Roth BL, Baumann $\mathrm{MH}$. Development of a rationally designed, low abuse potential, biogenic amine releaser that suppresses cocaine self-administration. J Pharmacol Exp Ther. 2005; 313:1361-1369. [PubMed: 15761112]

Rush CR, Stoops WW, Hays LR. Cocaine effects during D-amphetamine maintenance: a human laboratory analysis of safety, tolerability and efficacy. Drug Alcohol Depend. 2009; 99:261-271. [PubMed: 18926645]

Shearer J. The principles of agonist pharmacotherapy for psychostimulant dependence. Drug Alcohol Rev. 2008; 27:301-308. [PubMed: 18368612]

Shearer J, Wodak A, Mattick RP, van Beek I, Lewis J, Hall W, Dolan K. Pilot randomized controlled study of dexamphetamine substitution for amphetamine dependence. Addiction. 2001; 96:12891296. [PubMed: 11672493]

Shearer J, Wodak A, van Beek I, Mattick RP, Lewis J. Pilot randomized double blind placebocontrolled study of dexamphetamine for cocaine dependence. Addiction. 2003; 98:1137-1141. [PubMed: 12873248]

Silagy C, Lancaster T, Stead L, Many D, Fowler G. Nicotine replacement therapy for smoking cessation. Cochrane Database Syst Rev. 2004; 3:CD000146. [PubMed: 15266423]

Vocci F, Ling W. Medications development: successes and challenges. Pharmacol Ther. 2005; 108:94-108. [PubMed: 16083966]

White R. Dexamphetamine substitution in the treatment of amphetamine abuse: an initial investigation. Addiction. 2000; 95:229-238. [PubMed: 10723851]

Woolverton WL, Johnson KM. Neurobiology of cocaine abuse. Trends Pharmacol Sci. 1992; 13:193200. [PubMed: 1604712] 


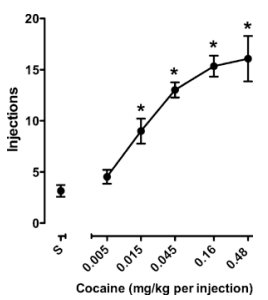

Fig. 1.

Cocaine self-administration under a PR schedule in rhesus monkeys $(n=4)$. Ordinate Mean $( \pm$ SEM) number of cocaine injections received, Abscissa available cocaine dose. Point above $S$ indicates number of injections earned during saline availability. ${ }^{*} p<0.05$, significantly different from saline 


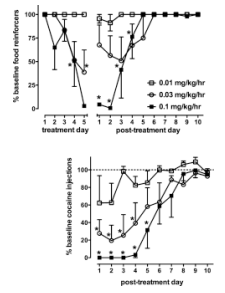

Fig. 2.

Food- and cocaine-reinforced responding during and after $d$-amphetamine treatment.

Ordinate number of food pellets (top) or cocaine injections (bottom), expressed as a percent of reinforcers earned under baseline conditions. Points represent mean $( \pm \mathrm{SEM})$ data for four monkeys. Abscissa day during (top only) or after treatment with one of three doses of $d$ amphetamine ( $24 \mathrm{~h}$ /day, i.v.). ${ }^{*} p<0.05$, significantly different from baseline reinforcers 


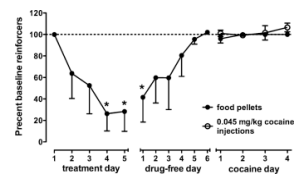

Fig. 3.

Food- and cocaine-reinforced responding during and after $d$-amphetamine treatment.

Ordinate number of reinforcers, expressed as a percent of reinforcers earned under baseline conditions. Points represent mean $( \pm \mathrm{SEM})$ data for three monkeys. Abscissa day during $d$ amphetamine treatment $(0.03 \mathrm{mg} / \mathrm{kg} / \mathrm{h})$, during a 6-day drug-free period and during cocaine self-administration. Other details as in Fig. 2 


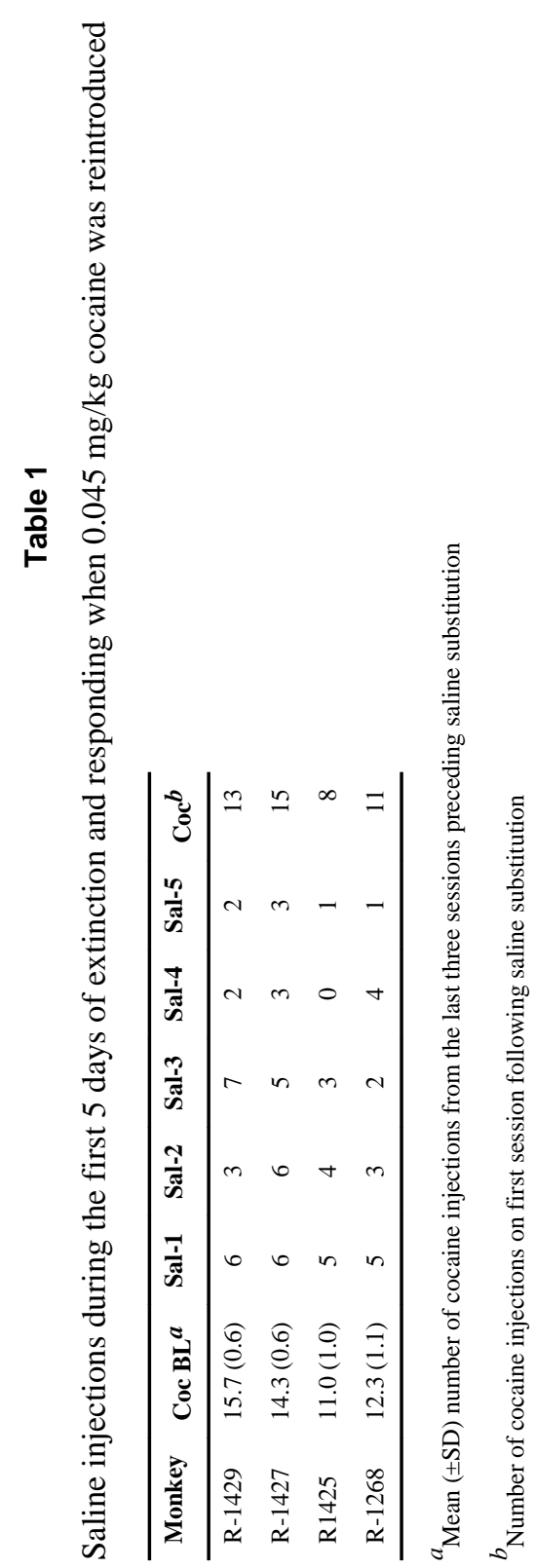

Psychopharmacology (Berl). Author manuscript; available in PMC 2011 June 24. 